\title{
A Peer-to-Peer Business Model for the Music Industry
}

\author{
Nick Gehrke and Markus Anding \\ University of Goettingen and University of Munich, Germany
}

\begin{abstract}
So far, the most profound problem of the internet-based distribution of music was the ease of copyright infringements (especially due to the emergence of illegal Peer-to-Peer exchange networks) and the little interest of users in commercial music offerings. Hitherto, the music industry tries to confront copyright infringements with technical restrictions and legal sanctions - up to now with minor success. Economic incentives for users to comply with copyrights and pay right-owners have not yet been discussed. The paper on hand introduces a Peer-to-Peer-based business model, which enables the compensation of copyright owners on the basis of economic user incentives and doesn't need technical or legal actions in order to enforce copyrights. Central in this model is the participation of users in the fees charged for the download. Therewith, the idea of Peer-to-Peer is being consequently advanced in the way that users not only participate in the process of distribution but also in the revenues generated. The user takes - besides the role of the music consumer - also the function of a merchant, enabling him to generate monetary revenues. Introducing this kind of incentive to a commercial filesharing system can be an approach to detract from the free systems' attractiveness for users sharing their files. The number of files offered in free filesharing systems will decrease since users will move to a system that offers a monetary remuneration.
\end{abstract}

Keywords: Peer-to-Peer, Filesharing, Business Model, Music Industry, Napster

\section{INTRODUCTION}

The discussion on the illegal use of digital music was boosted by the development of the MP3 file format ${ }^{1}$ and the emergence of the first popular music filesharing service Napster. Due to the character of Napster as a Peerto-Peer-Service and especially with new filesharing tools like Gnutella ${ }^{2}$ or Morpheus $^{3}$ users can exchange music files without the fear of legal

\footnotetext{
The original version of this chapter was revised: The copyright line was incorrect. This has been corrected. The Erratum to this chapter is available at DOI: 10.1007/978-0-387-35617-4_48 
consequences. An anonymous easy to use platform for the exchange of music files emerged, where every user can participate without having to pay the royalties to the music's originator. The exchange of music files became uncontrollable, not only because of the free Napster-Community but also because business models and commercial offerings of the music industry were not available. Only in the recent past, business models for the online distribution of music emerged and the former illegal Napster plans to become commercial. Besides Peer-to-Peer-based business models, the music industry also pursues other approaches as for instance the music platform Pressplay ${ }^{4}$. The paper on hand gives an introductory overview of existing business models for the electronic distribution of music in chapter 2 and introduces an improved business model based on the Peer-to-Peer approach in chapter 3. This business model differs from Napster in the way incentives are given to users to offer music files and exchange them within the system. An economic analysis of the business model completes the paper. A short summary and further research questions are given in chapter 4.

\footnotetext{
${ }^{1}$ See Fraunhofer Institute for Integrated Circuits (2002).

${ }^{2}$ www.gnutella.com.

${ }^{3}$ www.musiccity.com.

${ }^{4}$ www.pressplay.com.
}

\section{BASICS AND BUSINESS MODELS}

\subsection{Terminology}

A Peer-to-Peer-system can be characterised as a network which consists of different nodes having the same functionality. Peer-to-Peer systems are widely used for the decentralised supply of files and are - within this application - called filesharing systems.

Although there are other areas where Peer-to-Peer-technology can be applied, only filesharing systems gained major significance so far 5 . Filesharing systems in turn can have different architectures providing different levels of decentralisation. As least decentralised we term Peer-toPeer systems which employ index servers for the coordination of downloads. The index server distributes information to single peers on which other peers provide certain files. The server stores meta-data but not the data itself. A system with a central index server shows a high performance, since it accelerates the search for files within the network. However, the coordination of the file exchange among the peers will be interrupted if the index server fails. Thus, the system is vulnerable for technical attacks (like 
denial of service attacks) as well as for legal sanctions forcing the network to shut down.

As decentralised we term Peer-to-Peer-systems which operate without central index servers. Since all the information in this kind of network is completely decentralised, the search for files is less performing because several nodes have to be successively searched for the requested files. Further, the search delivers incomplete results because - for performance reasons - not the whole network is searched. An advantage of the system is its little vulnerability since no central index server is necessary and no instance can be target of legal actions.

A system which combines both architectures described can be termed as hierarchical Peer-to-Peer architecture ${ }^{6}$.

In order to employ Peer-to-Peer technology as a base technology for business models for online music distribution, only an architecture with a central index server is eligible because certain data cannot be stored completely decentralised. Especially standing data and account information of the system's users need to be stored centrally to avoid manipulation and redundancy.

The paper on hand describes a new Peer-to-Peer approach towards business models for online music distribution. The term business model has not yet been well defined in business literature. According to Wirtz, a business model defines - on an abstract level - which resources a company uses and how these resources are transformed into products through the company's production process ${ }^{7}$. The business model can be split into different partial models like the distribution model, the production model and the revenue model.

Thus, business models on the one hand describe the strategies of a company with respect to its external interfaces - the markets for products and production factors. On the other hand, business models deal with internal processes and organisational issues. Talking about business models for online music distribution, the following discussion focuses on the sales strategy (distribution- and revenue model), since especially the distribution of music - even more than its production - has changed with the emerging internet and Peer-to-Peer technologies. Further, generating revenues became more difficult for media companies due to the character of the internet as a "free lunch"-market.

\subsection{Service offerings and revenue models of business models for online-music distribution}

Presently, online music can be downloaded for free using widespread Peer-to-Peer filesharing systems. Commercial online music offerings have to compete with these free systems and must define their service offerings 
accordingly. Three substantial components can be distinguished in the online distribution of media products, which can also be found in the distribution of online music ${ }^{8}$.

1. Core Content as the main product

2. Add-On Content as product supplements

3. Information Content as content which describes content 1 and 2 (meta data).

Figure 1 tries to depict this distinction for an online music distributor.

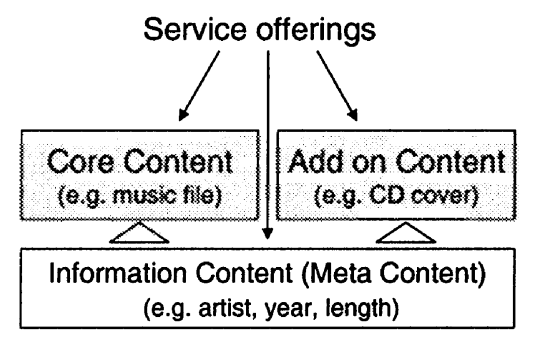

Figure 1: Service offerings of online music distributors

The design of a service offering which can compete with free systems and which - at the same time - consumers have a willingness to pay for, has so far been an unsolved task. The reason is that commercial distributors and illegal filesharing systems offer an identical product - with the difference that the first ones have to comply with copyrights and charge users for the service, the latter ones don't.

In order to comply with the copyright of digital music files, the music industry has developed Digital Rights Management Systems (DRMS) ${ }^{9}$. These DRMS are to control the usage of music files by limiting the number of playbacks, restricting the playback time, preventing files from being burnt on a CD or in other ways. DRMS allow the music industry to offer music files in various editions according to the usage rights granted.

Bearing in mind that users can easily access digital music files in a nonprotected file format (e.g. MP3) for free, we have to ask why users should register with commercial offerings and pay for music files whose usage - in addition - is restricted by DRMS. Shirky mentions that „The musics industry's set of schemes, called Digital Rights Management, is an attempt to force music files to behave less like ones and zeros and more like albums and tapes $[\ldots]$ to bring the inconvenience of the physical world to the internet, in other words",10.

To stimulate the user's willingness to pay, commercial offerings have to generate additional value (e.g. by providing additional add-on content or information content) in comparison with free sources. Defining this additional value is not an easy task. Taking measures for quality assurance, for instance a reliable download mechanism, is also an option for free 
filesharing systems and doesn't offer differentiation potential to commercial offerings. Further, users are inclined to utilise additional value offered by commercial services and then download the music for free from the free filesharing system.

\subsection{State of the Art in business models for online music distribution}

In the following we describe the current state of the art in commercial offerings for online music.

In contrast to Peer-to-Peer technology, which is commonly used by illegal offerings, commercial online music offerings predominantly employ the model of the Music Service Provider (MSP).

The MSP model is based on the traditional client/server architecture. A direct exchange of files between users does not take place. A typical example of this model is Pressplay (www.pressplay.com), which started its activities in December 2001. Also Musicnet (www.musicnet.com) has implemented the MSP-business model, but offers music of other artists than Pressplay. Users of both platforms pay a monthly fee and are allowed to consume music in different ways. The pricing model of Pressplay offers different membership levels ${ }^{11}$. All music files which are offered as downloads are protected by a DRMS and cannot be used as freely as common MP3-files.

The business model of Napster can be interpreted as an approach to commercialise the "free lunch" community, which has grown to more than 70 million users before it was closed by the court. Napster wants to continue the Peer-to-Peer model and wants to enable users to directly exchange music files. In contrast to the former free Napster system, users have to pay a monthly fee for a number of files that can be downloaded from other users. The music files in the Napster-network are distributed in an own DRM file format (NAP format) ${ }^{12}$, preventing the files from unrestricted usage. Figure 2 visualises the new business model of Napster.

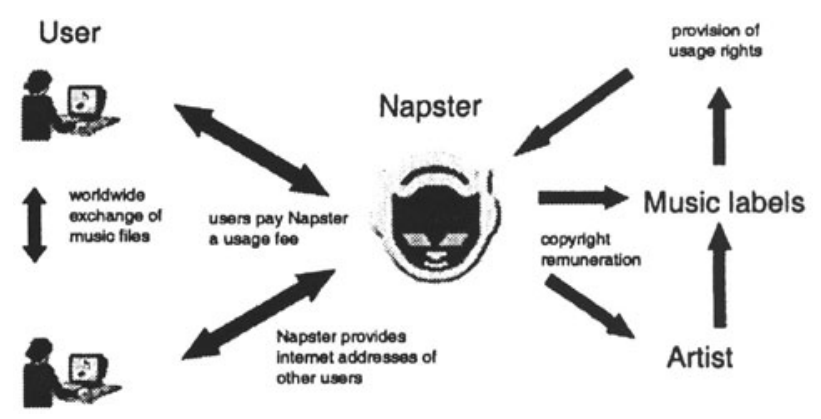

Figure 2: The new business model of Napster ${ }^{13}$ 
Since Napster is based on a Peer-to-Peer architecture, music files are stored decentrally and not on a central server as for instance in the Pressplay platform. The index server of Napster has to assure that the exchanged songs are counted and remuneration is paid to copyright owners. All the business models mentioned provide the user with an equal product: a DRM-protected and usage restricted music file. Whether this product is provided by a MSP or a Peer-to-Peer model doesn't matter to the user. It is questionable, if these business models can compete with illegal but free services, since the latter provide unrestricted files for free.

5 FATTAH systematises Peer-to-Peer collaboration, Applications-Interaction Systems and Resource Utilisation as domains for Peer-to-Peer applications. See Fattah (2002).

${ }^{6}$ See Hong 2001, p. 240.

${ }^{7}$ Wirtz (2001), p. 50.

${ }^{8}$ See Brandtweiner (2000), p. 114.

${ }^{9}$ See Buhse (2001), p. 386.

${ }^{10}$ Shirky (2001), p. 33.

${ }^{11}$ See http://news.com.com/2100-1023-277176.html.

${ }^{12}$ See http://www.napster.com/newnapfaq.html.

${ }^{13}$ According to http://www.spiegel.de/netzwelt/technologie/0,1518,108242,00.html.

\section{A NEW BUSINESS MODEL}

The business models described so far are not yet highly elaborated and neglect important requirements of online music distribution. Before introducing a new business model, we want to discuss certain requirements for online music distribution. In the following we describe the Peer-to-Peer business model developed on the basis of these requirements and put emphasis on the explanation of its revenue model. Because of advantages of the Peer-to-Peer-model over the MSP model (independence of certain music labels, less technical restrictions ${ }^{14}$ ), the developed business model is based on the Peer-to-Peer architecture.

\subsection{Requirements}

We can derive requirements for Peer-to-Peer business models from the transaction process taking place among participants of the network. The transaction process consists of different phases and can be depicted as in Figure $3^{15}$.

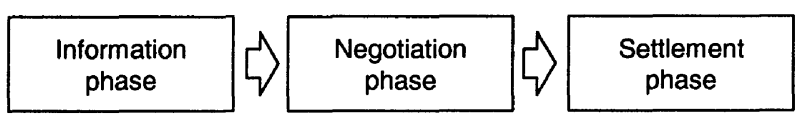

Figure 3: Phases of a transaction process 
Prior to the transaction process, the production of music content takes place and has to be taken into additional consideration because the sales transaction influences the production phase. The costs occurring in the production phase have to be recovered within the sales process to make production economically reasonable.

1. In the information phase the user collects information about potential offerings. These can be product information, prices and qualities.

2. In the negotiation phase the transaction partners agree on certain transaction parameters and design a contract.

3. In the settlement phase the exchange of goods takes place and the participants check if the delivered quality matches the contractual agreement.

In the following, we want to analyse each of these phases for requirements of the transaction participants. In the exchange of digital music, normally three actors participate: the originator (or rights owner), the supplier and the consumer.

In the production phase, the later consumers of the product require a high production quality. If not only the production but also the conversion of the music into portable file formats (MP3) and the definition of meta data ${ }^{16}$ are part of the production phase, we find playback quality (which depends on the compression) and correctness of the meta data as additional quality requirements.

Other requirements for Peer-to-Peer business models relate to the information phase. The consumer collects information on a future transaction and requires a certain quality of the transaction. This requirement relates to the transaction service, i.e. the Peer-to-Peer system and its infrastructure. The Peer-to-Peer service should offer uninterrupted downloads and a fast search mechanism as well as a broad range of music files.

The settlement phase is characterised by the requirement of the originator, who needs to recover the production costs with negotiated sales revenues. Since the originator and the supplier are different participants in the transaction, the originator can hardly enforce his demand for remuneration. The problem gets worse if the supplier gives away the music file for free and enables a free lunch market. If the originators are permanently not remunerated, they won't have an incentive to produce music content and the market might fail ${ }^{17}$. Thus, remuneration of the originator can be stated as a basic requirement for online music distribution. In order to enforce remuneration of the originator, basically three options are given: technical restrictions, legal sanctions and economic incentives.

- Technical restrictions (on the basis of DRM-systems) prevent the illegal usage of music content ex ante.

- Legal sanctions punish the illegal usage of music content ex post. Legal sanctions are hardly to assert - specifically with respect to single users of 
Peer-to-Peer systems. Generally - in relation with the threat of high penalties - they deter users ex ante from illegal usage.

- Implementing economic incentives is the supplier's most promising option for inducing users to copyright-conforming behaviour. Users tend to only favour legal usage of music content if it comes along with economic benefits. Because of the difficulty to implement economic incentives against the background of free Peer-to-Peer filesharing services, no such concept has yet been developed.

Current business models are solely based on the first two options. Every commercial music offering today employs DRMS for copyright protection. The well known legal actions of the music industry against Napster show that legal means are also common to enforce copyrights. In contrast to that, the Peer-to-Peer business model presented in this paper is based on the third option - economic incentives.

To assure the proper functioning of the service, users must be given incentives to participate. Thus, we state user incentives as another requirement for online music offerings. Free filesharing systems show the phenomenon that more users request music files than offer music files. This is because offering music files in a free system doesn't directly generate utility for the user. However, a business model for online music distribution should strive for a balance between supply and demand of music files.

The requirements defined for a Peer-to-Peer business model for online music distribution can be summarised as follows (see Table 1).

1. Compliance with copyright and remuneration of the copyright owner

2. Quality assurance

a. of the service (performant search, reliable download, etc.)

b. of the product (correct meta data, high quality of the music file)

3. Incentives for users to participate in the service

Table 1: Specific requirements for Peer-to-Peer business models for online music distribution.

\subsection{The concept}

In the following, we want to describe the distribution- and revenue model of the presented business model. Since the concept is a commercial approach, not a pure Peer-to-Peer system comes into question since a central server is needed to handle user- and accounting data. Central elements of the model are user accounts, where monthly amounts are paid in by users and fees for single downloads are deducted (pay per download). These fees are paid to the copyright owner, the supplier of the service and the user from whose computer the file is downloaded.

Figure 4 depicts an example of the download process' logic exemplarily assuming a download fee of 10 cent per file. The user accounts are logically 
assigned to single users but will physically be managed by the central instance as for avoiding manipulation.

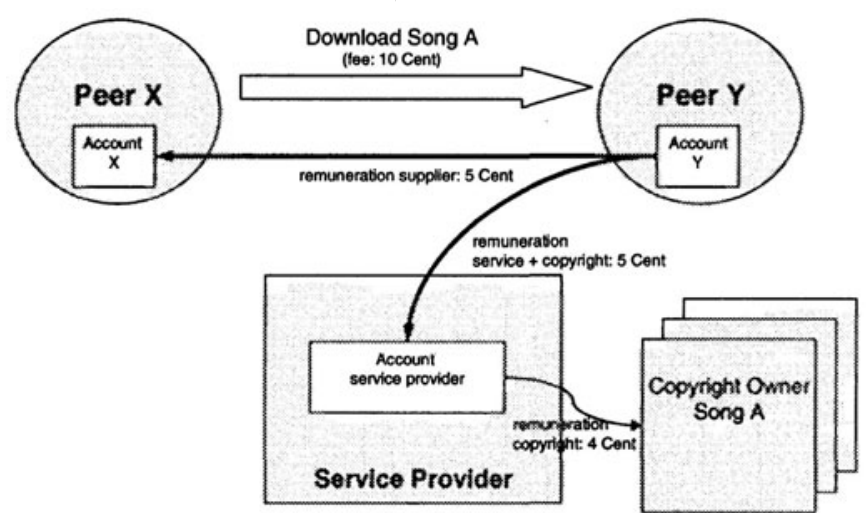

Figure 4: Distribution- and revenue model

Peer Y downloads a music file with song A from the computer of peer X. Beforehand, the location of the song was determined by the central index server which is not depicted in the figure. The system deducts an amount of 10 cents from user Y's account, which was previously loaded with a deposit. The amount of 10 cents is shared among the providing user $\mathrm{X}$ ( 5 cent) and the service provider ( 5 cent). The service provider determines the owner of the copyright for song A and forwards a share of the collected 5 cent fee. The amount of 5 cent paid to user $X$ are credited to his account and can be spent on user X's downloads.

\section{Protection of copyright owners and remuneration}

The presented concept does not employ DRMS or legal actions in order to protect copyright owners. By sharing the generated revenues among copyright owners and users, the concept establishes economic incentives for users to participate in the system and pay for the consumed music. Since downloaded music files include the potential to generate revenues for the user, he is willing to pay for music files in advance.

If the user is not able to withdraw the revenues earned with other user's downloads and collected on his account, all money paid in by users will eventually be transferred to the copyright owners and the service provider. With each download taking place, a share of the money retained in the system flows off to the copyright owners. Users, whose download volume exceeds the volume of uploads they made in the system, have to deposit new money to their accounts to keep them balanced. In order to advance the system and not only limit the users spending options to music files, the users could be allowed to spend collected money in participating online shops and buy related products like CDs or merchandising articles. 
Quality assurance

The quality of the Peer-to-Peer service strongly depends on its architecture. Current Peer-to-Peer architectures already comprise high performance file search and an optimised download mechanism. The presented Peer-to-Peer concept can easily be constructed on the basis of these already established mechanisms ${ }^{18}$. However, the model of sharing revenues with users does not enable music file quality assurance offhand. A mechanism for control and sanction is necessary, which ensures, that the meta data of each music file is defined correctly and the right copyright owner is specified for identification by the service provider. Beyond pure technical means, a concept for user rating is imaginable, enabling users to assess one another after download transactions.

\section{Incentives to participate}

By enabling users to participate not only in the distribution of music files but also in the fees raised for single file downloads, users get an economic incentive to participate in a commercial Peer-to-Peer filesharing network and eventually the remuneration of copyright owners becomes possible. Beyond that, the concept addresses the problem that in a free filesharing system normally only a marginal number of users actually provide the network with download offerings and the major part of the community solely consumes the content. Users who provide the network with ample download offerings will be remunerated proportionately when participating in the proposed Peerto-Peer system. Thus, users holding large amounts of music files will rather offer their content in the commercial system instead of providing a free system which they cannot expect any refund from.

\subsection{Economic assessment}

In order to assess the proposed concept from an economic point of view, we want to take a look at its specific features. Two characteristics of the business model can serve as starting points.

First, current business models like the Music Service Provider or the new Napster business model face a heavy competition with free filesharing services. One of their basic problems is to build an incentive for users to participate in a commercial service they have to pay for and not downloading their songs for free. A theoretic approach, suited to analyse the incentives of the business model proposed in this paper, is the Principal Agent Theory. Second, Peer-to-Peer filesharing systems, whether free or commercial, draw their whole value from the number of users participating in the system. Since the value of the network is almost perfectly correlated with the number of users offering their content, the theory of network effects can be applied to analyse the system. 
Incentives and the Principal Agent Theory

The proposed business model establishes an incentive system for participating users which can be analysed using Principal Agent Theory ${ }^{19}$. The originator or copyright owner of music content can be considered the principal while the participating users take the function of agents. The mattering question is why the presented business model incorporates a better incentive system than the currently existing business models. For the purpose of comparing the current systems and the new approach we define the incentive scheme of a fictive reference business model. It may have the following simple structure:

(1) A music file costs a user $p$ monetary units (pay per download). A selling on of the file may not be possible. This model does not necessarily have to be based on a Peer-to-Peer infrastructure but can also employ the MSP model.

The revenue model of the presented business model can be formulated as follows:

(2) A music file costs a user p monetary units. A selling on of the file to any other user is possible. The selling user gets a share of $\alpha^{*} p$ (with $0 \leq \alpha \leq 1$ ) of the sales revenue and the copyright owner and service provider get a share of $(1-\alpha)^{*}$ p. Because of the possibility of selling on the file, a Peer-to-Peer infrastructure is obligatory. In order to explain the advantage of the second model, we can take a look at the participation condition of the Principal Agent Theory $^{20}$. The participation condition states, if an agent will participate in a service under certain circumstances. Therefore, the utility from participating in the service is to be compared to the reservation utility. The reservation utility is the utility from participating in an alternative service by which the user can equally satisfy his wants. The service delivering this reservation utility will be the free filesharing service. First, the incentives to participate in revenue model (1) are to be analysed. The participation condition is:

$$
u-p \geq u
$$

With $p$ being the price of the music file and $u$ being the utility which results from buying the file. The left side of the unequation represents the utility from participating in the commercial service. The user has to pay a fee which is deducted from his utility. The right side represents the utility from participating in a free filesharing service. Obviously, the utility from participating in the commercial system will never exceed the utility from registering with a free service. Consequently, the revenue model (1) does not show incentives for participation. This circumstance can be considered the basic problem of the music industry's online business models.

The participation condition of revenue model (2) can be formalised as follows: 


$$
\alpha m p-p+u \geq u \Leftrightarrow \alpha m \geq 1
$$

With $\alpha$ being the share of a music file's price, the user can retain when selling on the file. $m$ states, how often the file will be downloaded by other users, thus generates revenues for the selling user. It is to be taken into consideration, that $\mathrm{m}$ is a stochastic variable, since the user does not know ex ante, how many other users will download the song from him. m has to be individually estimated by each user and is subject of subjectivity. Each user compares his ex ante stochastic revenues, which can be considered lottery gains, with deterministic purchase price of the music file. Thus, users estimating $\mathrm{m}$ sufficiently high will meet the participation condition. Beyond that, the unequation above allows statements on about the user's revenue share $\alpha$. In order to maintain the participation condition fulfilled over time, the factor $\alpha$ should be adjusted by the service provider depending on an assumed number of further selling opportunities. If a music file is already wide spread over the system, the users will reduce their expected resalerevenues. Users, buying a music file which is already wide spread will not expect high potential for resale. In order to keep the file traded among users, $\alpha$ should be increased as the file diffusion increases so as the product of $\mathrm{m}^{*} \alpha$ stays constant. Generally, this revenue model can be compared to a pyramid scheme which starts over with each music file entering the system. Users who acquire the file in a late stadium face declining revenue expectations due to a sinking number of users not yet possessing the file. Finally, revenue model (2) shows a better incentive structure than revenue model (1), it even enables users to earn net gains after acquiring a music file.

\section{Reinforced network effects}

Peer-to-Peer filesharing systems generally are subject to network effects $^{21}$ which we expect to be significantly reinforced in the presented business model due to the specific revenue model. This reinforcement effects music files (as they are network products) as well as the Peer-to-Peer system itself. Because of the monetary remuneration of the participants, their interest in the music itself is not longer their only incentive for participating in the service. The result is, that users not only demand music songs because of their interest in music but also valuate songs on the basis of their potential to generate profits. Thus, an initially popular music file will generate additional demand due to potentially high resale-revenues and will even be acquired by users who don't have interest in the music itself. Therefore, the diffusion of the file within the network will take place much faster than in conventional free filesharing systems. Instead, less demanded music files, which don't embody potential resale revenues, and predominantly impose download fees on users, will be less demanded as in free filesharing systems. Consequently, direct network effects with respect to single music files are 
reinforced and popular music files spread much faster, unpopular files spread curbed within the filesharing system. Thus, a stronger polarisation into popular and unpopular music files takes place. Further we can expect stronger network effects with respect to the filesharing system itself.

${ }^{14}$ Imagine the simultaneous access of several 100.000 users to a single MSP, for whom it is not possible to provide a sufficient bandwith. A Peer-to-Peer network can handle these requests easily.

${ }^{15}$ See Schmid (2000), p.184.

${ }^{16}$ Meta data like title of the song, artist, smaplpe rate should match the actual properties of the music file.

${ }^{17}$ See Kiefer (2001), p. 80.

${ }^{18}$ Download can be split among several users providing the same file in order to optimise download speed fort he requesting user.

${ }^{19}$ See Picot/ Reichwald/ Wigand (2001), p. 56.

${ }^{20}$ See Richter/ Furubotn (1999), p. 203.

${ }^{21}$ See Köster (1998) for details on network externalities.

\section{SUMMARY}

The presented Peer-to-Peer business model tries to enable the commercial distribution of online music by establishing economic incentives for users. Beyond the technical aspect of Peer-to-Peer filesharing, the presented model is consequently advanced so that users not longer only participate in the distribution but also in the generated revenues. This approach extends the - so far - pure technical Peer-to-Peer model by an economic Peer-to-Peer concept. However, the presented model cannot be considered a solution for the legal problems with the free filesharing systems. Only the incentive structures of the new model dominate the ones of free filesharing systems. In the following, we want to summarise economic and non-economic arguments supporting the presented business model:

- Since the user has the chance to compensate the fees he paid for downloads by selling on the music files, it is possible that he eventually can acquire the file for free. Clearly this cannot happen for all users of the service, but for single participants there is a possibility of complete compensation or even net gain. This gambling factor can create an revenue illusion that tempts users to participate in the service.

- In addition to the gambling factor, the possibility of generating net gains gives the user the feeling of being integrated into the system in a fair way. This supports the system acceptance.

- Due to the specific incentive scheme of the service, users wont offer their files in free filesharing systems anymore but participate solely in the 
commercial service. This will deprive free filesharing systems of music supplies, making them even less attractive for users.

- Since the presented approach is a commercial service that remunerates copyright owners, each participant can be sure not to act illegally.

The presented Peer-to-Peer business model aims at implementing better incentives than current business models, superseding illegal free filesharing systems at the same time. Further research is to be conducted in the field of how the prices of single music files can be determined and which criteria should define the share of download revenues paid to the supplying user. Additionally it will have to be analysed if these parameters should be set by the service provider or if users should have the opportunity to negotiate on prices themselves.

\section{REFERENCES}

Brandtweiner, R. Differenzierung und elektronischer Vertrieb digitaler Informationsgüter, Duesseldorf, 2000.

Buhse, W. Systematisierung von Geschäftsmodellen für Online-Musik unter Berücksichtigung von Marktunsicherheiten, in:

WIRTSCHAFTSINFORMATIK 432001 4, pp. 383-392.

Fattah, H.M. P2P: how Peer-to-Peer-technology is revolutionising the way we do business, Chicago, 2002.

Fraunhofer Institute for Integrated Circuits. MPEG Audio Layer-3, http://www.iis.fhg.de/amm/techinf/layer3/, accessed on 20.03.2002

Hong, T. Technical Topics - Performance, in: Oram, A. (Ed.): Peer-to-Peer, Harnessing the Power of Disruptive Technologies, p. 240.

Kiefer, M.L. Medienökonomik, Munich, 2001.

Köster, D. Was sind Netzprodukte? - Eigenschaften, Definition und Systematisierung von Netzprodukten, Discussion Paper FS IV 98 - 10, Wissenschaftszentrum Berlin, 1998.

Minar, N. / Hedlund, M. A Network of Peers, in: Oram, A. (Ed.): Peer-toPeer, Harnessing the Power of Disruptive Technologies, pp. 3-21, Sebastopol.

Picot, A./ Reichwald, R./ Wigand, R.T.: Die grenzenlose Unternehmung, 4. Ed., Wiesbaden, 2001.

Richter, R. / Furubotn, E. Neue Institutionenökonomik, 2. Ed., Tuebingen, 1999.

Schmid, B.F. Elektronische Märkte, in: Weiber, R. (Ed.): Handbuch Electronic Business, Wiesbaden 2000, pp. 179-208.

Shapiro,C./ Varian H.R. Information Rules, Boston, 1998. 
Shirky, C. Listening to Napster, in: Oram, A. (Ed.): Peer-to-Peer Harnessing the Power of Disruptive Technologies, Sebastopol, 2001.

Wirtz, B. Medien- und Internetmanagement, 2. Ed., Wiesbaden, 2001.

Zerdick, A./ Picot, A./ Schrape, K./ Artopé, A./ Goldhammer, K./ Lange, U.T./ Vierkant, E./ López-Escobar, E./ Silverstone, R.: ECONOMICS Strategies for the Digital Marketplace, Berlin a.o., Springer 2001. 